\title{
TEMPO E ESPAÇO COMO EXPERIÊNCIA NO \\ MUSEU
}

\begin{abstract}
Resumo
$O$ artigo discute como a categoria historiográfica do tempo se manifesta em espaços expositivos. O estudo de duas instituições - o Museu Histórico Nacional (MHN), localizado na cidade do Rio de Janeiro, e o Museu de Artes e Ofícios (MAO), em Belo Horizonte - analisa a interposição entre a concepção do desenho espacial expositivo e o conceito narrativo, focalizando a representação temporal em ambas as exposições de longa duração. Por meio do processo de espacialização de acervos orientado pelo conceito curatorial, as representações de tempo ganham materialidade como imagens e se oferecem à experiência sensível do público.
\end{abstract}

\section{Palavras-chave}

Museologia, Historiografia, Temporalidade, Espaço, Exposições.

\section{Letícia Julião²}

Lucas Vasconcellos ${ }^{3}$

\begin{abstract}
The article discusses how the historiographical category of time manifests itself in exhibition spaces. The study of two institutions - the $\mathrm{Na}$ tional Historical Museum (MHN) in Rio de Janeiro and the Museum of Arts and Crafts (MAO) in Belo Horizonte - analyzes the interposition between the spatial design of the exhibition and the narrative concept, focusing on temporal representation in both long-term exhibitions. Through the curatorial process that locates the collections in space, the representations of time gain materiality as images and offer themselves to the sensitive experience of the public.
\end{abstract}

\section{Keywords}

Museology, Historiography, Temporality, Space, Exhibitions.

\section{Introdução}

Museus são lugares onde o tempo e o espaço se articulam na produção de uma narrativa mediada pela visualidade. $A$ arquitetura tem um papel decisivo nesse processo, constituindo uma manifestação expressiva, como destaca Giebelhausen (2008), de distintos paradigmas que regeram e regem o funcionamento dessas instituições, dando a ver processos de rupturas e continuidades ao longo da história. Dos edifícios do final do século XVIII que sobrepunham elementos da Antiguidade - espécie de herança espiritual - a estruturas modernas,

1 O artigo é resultado da pesquisa "História, herança cultural e temporalidade: conhecimento e imaginário museológico", desenvolvida com o apoio da Fapemig - Fundação de Amparo à Pesquisa de Minas Gerais.

2 Professora Adjunta da Escola de Ciência da Informação da UFMG, atuando especialmente no Curso de Graduação em Museologia.

3 Graduando do Curso de Museologia - Escola de Ciência da Informação - UFMG 
Tempo e Espaço como Experiência no Museu

próximas aos ambientes de confinamento como prisões, hospitais analisados por Foucault, os museus se inscrevem nas transformações urbanas no século XIX, com sua arquitetura de ferro e vidro, apropriada ao controle da massa de cidadãos, estabelecendo-se como lugares de celebração de rituais civilizadores. Essas configurações arquiteturais, consolidadas no século $\mathrm{XIX}$, favoreciam, por conseguinte, determinados ordenamentos das coleções no espaço expositivo. Além de percursos ao longo de um itinerário processional, predominantemente cronológico, a decoração arquitetônica simbólica também contribuía para enquadrar a classificação de coleções. Se em fins do século XIX, a arquitetura de museus é distintiva da nação e poder industrial, nos séculos seguintes, $X X$ e $\mathrm{XXI}$, responde às demandas das coleções e do público ampliado e diversificado, tendo na ideia do cubo branco e na edificação espetacular seus emblemas. (GIEBELHAUSEN, 2008).

Há, de fato, uma convergência entre arquitetura e propósitos expositivos; o design espacial do museu traduz ideias e valores, molda padrões de movimentos e comportamentos (HILLIER;TZORTZI, 2006). Bennett (2006) sugere que, desde o seu surgimento no período moderno, os museus conformam regimes de visualidade, que condicionam práticas do olhar, em particular, formas de visões cívicas.

Nessa gramática visual do museu, Castillo (2008) reconhece que a exposição é, por excelência, uma composição espaço temporal que se inscreve na esfera da arquitetura. Compreendê-la pressupõe admitir que as relações espaço-temporais não surgem apenas da experiência perceptiva e intelectual do sujeito diante da obra, mas de uma totalidade que é resultado do entrelaçamento da experimentação sujeito/obra com o espaço habitado por ambos.

$\mathrm{Na}$ conjugação museal de espaço, tempo e visualidade, este artigo propõe discutir as formas de representação do tempo em exposições de longa duração de dois museus - o Museu Histórico Nacional (MHN), no Rio de Janeiro e o Museu de Artes e Ofícios (MAO), em Belo Horizonte. A intenção é problematizar ambas as exposições à luz de categorias da historiografia contemporânea, particularmente a noção de regime de historicidade, tal como propõe Hartog (20l3).

Compreende-se regime de historicidade como a forma na qual a sociedade lida com o passado; como organiza a experiência do tempo, criando uma articulação entre passado, presente e futuro, designativa da consciência que a comunidade humana tem de sua própria historicidade (HARTOG, 20I3). Os museus, dentre outras instituições, são espaços que permitem a sociedade inscrever visual e materialmente as maneiras pelas quais percebe e reage à passagem do tempo, ao sentido histórico de sua existência.

Em particular, as exposições conferem materialidade às experiências da sociedade com o tempo. Elas funcionam como evidências importantes para se compreender como a sociedade organiza uma ordem do tempo. É nessa perspectiva que o artigo busca estabelecer um diálogo entre a concepção do desenho espacial e o conceito narrativo, observando como objeto, espaço e temporalidade se relacionam e norteiam o conceito expositivo no Museu Histórico Nacional (MHN) e no Museu de Artes e Ofícios (MAO). 


\section{Museu como espaço e tempo}

Distintas configurações do espaço corresponderam, ao longo da história, a diferentes formas de se conceber museus, a diferentes maneiras de se espacializar as coleções. Do abrigo de coleções em gabinetes de curiosidades aos museus nacionais; do cubo branco às experiências de museus que se abrem para territórios extramuros, amalgamando-se aos ambientes do cotidiano, o museu, não importa sua tipologia ou temática, é sempre uma concepção e construção de espaço. Segundo Desvalées; Mairesse (20I3) a arquitetura museal tem como uma de suas atribuições conceber e construir um espaço destinado a abrigar as funções específicas de exposição, preservação, estudo, gestão e do acolhimento de visitantes. Segundo os autores:

Desde a invenção do museu moderno, a partir do final do século XVIII e início do XIX, e, paralelamente, a partir da reconversão de antigos prédios patrimoniais, desenvolveu-se uma arquitetura específica que, especialmente pelas suas exposições temporárias ou de longa duração, vincula-se às condições de preservação, de pesquisa e de comunicação das coleções. Esta arquitetura ficou evidente tanto nas primeiras construções desse tipo quanto nas mais contemporâneas. $O$ vocabulário arquitetônico condicionou, ele mesmo, o desenvolvimento da noção de museu. (Desvalées; Mairesse. 2013: 29).

Das distintas concepções de espaços expositivos, Castillo (2008) identifica, no inicio do século $X X$, um grande esforço de padronização da linguagem comunicativa dos museus, que produz um repertório formal de espaços puristas, como legado racionalista. Os investimentos metodológicos e didáticos da Bauhaus, formulados sob a égide de uma linguagem universal, assim como o surgimento do Museum of Modern Art (MoMa) exemplificam claramente essa nova estética expositiva, nos anos de 1930. É nesse contexto que a concepção do cubo branco ganha reprodutibilidade nos museus de arte.

\footnotetext{
Após a Exposição Internacional:Arquitetura Moderna, realizada no Museum of Modern Art (MOMA), em 1932, sob organização do arquiteto Philip Johnson e do historiador Henry Russel, (...) o museu, como objeto arquitetônico, deveria ter o mesmo peso de qualquer outra tipologia arquitetônica pública urbana e, acima de tudo, ser funcional, responsabilizando-se assim pelas respostas espaciais às solicitações do espectador. Sua concepção projetiva seguiria, pois, os princípios racionalistas, devendo resultar, portanto, num espaço neutro, flexível, fechado, iluminado artificialmente, perfazendo o que hoje conhecemos como cubo branco. (CASTILLO, 2008: 62).
}

Em 1937, Herbert Bayer, designer oriundo do período de efervescência da Bauhaus, produziu um ensaio, intitulado Fundamentals of Exhibition Design, no qual explicita o papel da arquitetura e do design na construção de fluxo, perspectiva e campo de visão das exposições.

When the exhibition material is already grouped in a reasonable sucession, then the direction of visitors will follow in a free and unaffected manner: by means of the forceful and effective swinging motion of direction arrows, by means of mechanically produced sounds, by means of automatic repetition or playing of speaking records, etc. An unseen direction will be easily accomplished by 
placing interesting and outstanding things at points where they wiimmediately be observed. (BAYER, 1937: 19 ). ${ }^{4}$

Em relação ao fluxo de público, propõe percursos em que a disposição dos módulos de exibição observa o sentido linear, com uma única entrada e saída no espaço expositivo. Bayer acreditava que a fruição se desenvolveria de uma maneira eficaz, uma vez que o público entenderia o conceito expositivo inscrito na espacialidade.

Em razão provavelmente de seu trabalho com a diagramação e criação de fontes do alfabeto, defendia que o fluxo do visitante na exposição seguia o sentido da escrita e leitura nos padrões ocidentais:

The lettering and reading direction of visitors, for the moving spectador must be able to go logically in the direction of the writing. This problem is, of course, different for a people whose writing takes a different course.(BAYER, 1937: 19). ${ }^{5}$

As concepções normativas de BAYER (1937), especialmente a ideia de uma sucessão linear de objetos/fatos, convergem com argumentos de alguns autores que analisam a representação do tempo em narrativas expositivas. Para Preziosi (2006), o percurso em um museu se parece com um caminhar pela história, em uma sucessão de objetos que encenam não apenas a passagem do tempo, mas mudanças ou mesmo o desenvolvimento de formas, estilos, mentalidades.

Ao considerar que quase todos os museus são de história, Pomian $(2004)^{6}$ identifica três aspectos que se associam a essa condição. Os dois primeiros seriam a suposta autenticidade dos objetos, o que permite que sejam provas de determinadas afirmações, e a circunstância de serem objetos datados e localizados, segundo técnicas, escalas temporais variáveis. A terceira condição refere-se ao fato de

les objects son exposés en général selon l'ordre de leur sucessions dans le temps, de manière que le percours du visiteur, s'il reste conforme au programme que propose le musée, conduise des plus anciens vers les plus récent. Et cela signifie enfin que les formes postérieures son censées proceder des antérieures non pas de façon arbitraire mais selon des mécanismes propes à chaque domaine et dont on peut toujours fournir la description, preuves à I'appui. (POMIAN, 2004: 99) ${ }^{7}$

4 Quando o material da exposição já está agrupado em uma sucessão razoável, a direção dos visitantes seguirá de forma livre e natural: por meio do movimento convincente e efetivo da sinalização de direção, por meio dos sons produzidos mecanicamente, por meio da repetição automática ou da reprodução de registros de fala, etc. Uma direção invisível se efetivará com facilidade, pela disposição de coisas interessantes e excepcionais em pontos onde serão logo observados. (tradução nossa)

5 A direção de legendas e da leitura dos visitantes, para o espectador em movimento deve ser capaz de seguir logicamente a direção da escrita. Esta questão, claro, é diferente para pessoas cuja escrita tem um curso diferente. (tradução nossa).

6 O autor sustenta o argumento lembrando que os museus de mineralogia ou geologia, são museus de história da terra, museus da evolução das espécies são de história dos seres vivos, museus de antropologia, pré-história ou civilizações, são de história dos seres humanos, e assim por diante.

7 Os objetos são expostos, em geral, segundo a ordem de sua sucessão no tempo, de maneira que o percurso do visitante, se ele permanece conforme o programa que o museu propõe, é conduzido dos mais antigos para os mais recentes. E isso significa enfim que as formas poste- 
Os apontamentos de Pomian (2004) e Preziosi (2006) confícia Julião ideia de que a organização do espaço se conforma e também produz a percepção do tempo na exposição. Tem-se, portanto, como premissa que o espaço não é apenas um receptáculo das intervenções expositivas, mas constitui-se em elemento da narração, decisivo na sintaxe do discurso museal.

Como aparatos de exibição, que se organizam em torno de padrões de visualidade, os museus encerram a potência de modelar olhares, percepções e concepções que a sociedade tem do transcurso do tempo, de sua própria historicidade. São instituições exemplares para se compreender o alcance universal da comunicação das imagens, de que trata Knaus (2003). Diferentemente da escrita que exige uma habilidade específica, "a imagem possui um registro abrangente, baseado em um dos sentidos que caracterizam a condição humana"; razão pela qual é "capaz de atingir todas as camadas sociais ao ultrapassar as diversas fronteiras sociais" (KNAUSS, 2003: 99).

\section{Museu Histórico Nacional}

O Museu Histórico Nacional, criado em 1922, está instalado em um complexo arquitetônico de origem militar, no centro da cidade do Rio de Janeiro, em área estratégica para a defesa da cidade, conhecida como Ponta do Calabouço. Originalmente foi construída no local, em 1603, a Fortaleza de Santiago, seguindo-se outras ocupações e edificações: a Prisão do Calabouço (1693), a Casa de Trem (1762), o Arsenal de Guerra (1764), o Quartel para abrigar as tropas militares (1835) e o Arsenal de Guerra que permaneceu até 1908 na área. Por ocasião do centenário da Independência, a Ponta do Calabouço foi reurbanizada, e o conjunto arquitetônico foi ampliado e decorado para sediar o pavilhão da Exposição Internacional Comemorativa do Centenário, em 1922. No mesmo ano, eram abertas à visitação duas galerias do Museu Histórico Nacional, dotando o país de um museu dedicado à história nacional. ${ }^{8}$

À frente da criação do Museu e formação de seu acervo estava Gustavo Barroso, intelectual cearense, advogado e jornalista, que dirigiu a instituição de 1922 a 1959, com um breve interregno entre 1930 e 1932. Originalmente o acervo do Museu constituiu-se a partir de uma matriz antiquaria, reunindo, com o amparo da numismática, epigrafia, genealogia, heráldica, etc, coleções de objetos associadas a fatos e a personagens notáveis do passado brasileiro, com ênfase no período imperial. Orientou essa concepção do Museu a perspectiva historiográfica, formulada no século XIX, de que a nação brasileira constituía um prolongamento, na América, do Estado português e da civilização branca e europeia. Em particular, a nobreza e o exército, concebidos por Barroso como sustentáculos da nação, figuravam como segmentos privilegiados no colecionamento do MHN. (GUIMARÃES, 2003;ABREU, 1996).

O MHN reformulou sua exposição em diversas ocasiões, sendo que a primeira intervenção ocorreu em 1930, quando o agrupamento de antiguidades

riores são supostamente precedidas das anteriores não de maneira arbitrária, mas, segundo mecanismos próprios para cada área e no qual se pode sempre fornecer a descrição, evidência para apoiar-se (tradução nossa).

8 Informações disponíveis em (http://mhn.museus.gov.br/index.php/o-museu/). Acesso em 20 dezembro de 2017. 
idealizado por Barroso é substituído por uma exposição concebida cronologicamente, numa perspectiva da história como magistra vitae, ou seja, como fonte de exemplos para o presente. (MAGALHÃES, 2003). Nos anos 2000, ocorre a última mudança na exposição de longa duração, concluída em 2010 , quando se adotou "uma narrativa tributária de uma história de corte acadêmico, contrapondo-se francamente ao projeto passadista que dera origem ao Museu, nos anos de 1920" (JULIÃO, 2015) e, ao mesmo tempo, estruturando a narrativa em uma abordagem didática, voltada para o vasto público de visitantes do Museu.

A exposição é formada por quatro grandes módulos - Oreretama - que aborda os povos indígenas; Os Portugueses no Mundo, abrangendo o período de 1415 a 1822, da expansão marítima portuguesa à independência do Brasil; Construção da Nação - que trata do Estado Imperial até a proclamação da República e Cidadania em Construção - dedicado ao período republicano. Como fica evidente na sequência dos módulos, os quase dois quilômetros de percurso expositivo investem em uma história com início, meio e fim, sem interrupções temporais, apresentada de modo a conferir coerência ao passado da nação brasileira.

O circuito da exposição se apresenta em um continuum, no qual o visitante é conduzido sempre à vitrine ou ao módulo que está adiante. Não há percursos alternativos ou aleatórios. Como proposto por Bayer, o visitante no MHN percorre um caminho que possui uma única entrada e única saída, de modo que o desenvolvimento da narrativa expositiva se realiza sem riscos de desvios, leituras paralelas ou retornos.

O tempo sequencial da narrativa está ditado pela linearidade do espaço, constituindo um só elemento a concorrer para a construção da narrativa: uma história cronológica em que os fatos se sucedem em uma ordem submetida à lógica de causa e efeito. $O$ espaço conjuga-se ao conceito narrativo, configurando uma temporalidade fixada na ideia do progresso, no regime moderno de historicidade:

\footnotetext{
Pode-se dizer que se trata de uma narrativa fixada em um regime moderno de historicidade: abandona-se a ideia de exemplaridade, da qual se pressupõe a repetição dos fatos, para se fixar na existência de uma história no singular, entendida como processo, na qual os acontecimentos não se repetem, pois têm caráter único. $\mathrm{Na}$ articulação das dimensões do tempo, o futuro é convocado para explicar o passado (Hartog, 2013). No caso, é a expectativa da cidadania plena no país a razão de ser da experiência do passado. (JULIÃO, 2015:132)
}

O imperativo do espaço linear concorre de forma decisiva para a representação da temporalidade, nesse contexto. O percurso tematiza um movimento da história ditada pelas expectativas de uma comunidade de destino. Nessa configuração, vale notar, ainda que se busque assinalar alguns processos que se desenrolaram a contrapelo da história, a narrativa expositiva é conduzida sem rupturas espacial ou temporal, sem abertura para a justaposição de outros passados, outras temporalidades e outros sujeitos. Dois exemplos são emblemáticos. Índios e negros aparecem em tempos fixos da narrativa. Os primeiros habitantes abrem a exposição no módulo Oreretama e os negros, em uma sala 
dedicada à contribuição de sua cultura, no módulo Os Portugueses no Mundo, que aborda a empresa colonial na América Portuguesa e a formação econômica, política e cultural do Brasil. À exceção dessas duas abordagens, ambos os povos desaparecem da narrativa expositiva, permanecendo invisibilizados como sujeitos históricos ao longo do caminho sequencial da história representada.

\section{Museu de Artes e Ofícios}

O Museu de Artes e Ofícios (MAO), aberto à visita pública em 2006, localiza-se no hipercentro da cidade de Belo Horizonte.A instituição tem origem em uma coleção particular de cultura popular, especificamente associados ao trabalho pré-industrial no Brasil, datados entre os séculos XVIII e XX. A coleção pertencia a então presidente do Instituto Cultural Flavio Gutierrez (ICFG), Ângela Gutierrez, que esteve à frente da criação do Museu.

O Museu ocupa dois edifícios da antiga Estação Ferroviária Central da cidade, compondo o complexo arquitetônico da Praça Rui Barbosa, mais conhecida como Praça da Estação. Com estrutura neoclássica, os edifícios foram restaurados e adaptados para acolher o Museu, seguindo um programa museográfico e expográfico concebido pelo museólogo francês Pierre Catel.Ambos os prédios, situam-se nas extremidades da Estação Central da atual linha metroviária da cidade, a qual recebe, diariamente, intenso fluxo de transeuntes e usuários, majoritariamente da classe trabalhadora. Com a solução de paredes de vidro em ambos os edifícios, Catel buscou integrar o cotidiano da estação à narrativa da exposição, assegurando a visualização e a comunicação entre a estação central, que corta o museu ao meio, e os visitantes da exposição:

\footnotetext{
Em vez de um audiovisual sobre os assuntos, temos um trem que passa no meio do museu, que se depara com os minérios, com o mármore, com o granito, e isso vale por um audiovisual gigante, quando você tem o barulho, quatrocentos vagões que passam pelo meio do museu. Portanto, não estamos mais dentro daquela forma: onde está a etiqueta, para ler a referência? A referência passa diante de você. Ela vive diante de você. É essa noção do que é vivo, porque fomos postos junto aos vivos! Não se procurou retirar esse espaço museográfico do mundo cotidiano, do permanente. E um milhão de pessoas vão passar, tomar o metrô, por ano - os trens de mineração que atravessam o museu. (CATEL, 2005: 330).
}

Catel explicita em seu depoimento a intenção de explorar a implantação urbana do Museu como elemento capaz se estabelecer um diálogo potente entre interior e exterior, passado e presente, realidade cotidiana do trabalho atual e as artes e ofícios musealizados. Apesar de concebida pela arquitetura planejada para a expografia, a conexão entre o Museu e a plataforma da Estação Central não se efetivou na prática. As paredes de vidro permitem aos visitantes do museu visualizar a Estação, mas o mesmo não ocorre com os usuários do transporte público. Eles contemplam apenas silhuetas dos objetos do museu, uma vez que, em função da necessidade de proteger o acervo da luminosidade, 
as paredes de vidro estão revestidas de protetor em tom escuro. Do propósito de conectar a realidade urbana e o museu, resta apenas a exposição de alguns objetos em vitrine colocada fora do Museu, em plataforma desativada do metrô.

No interior dos edifícios, a exibição do acervo obedece a uma lógica temática, concebida a partir de ofícios. São 15 módulos, sendo 4 instalados no prédio A, que é a entrada do Museu: Ofícios do Transporte, Ofícios Ambulantes, Ofícios do Comércio e A proteção do Viajante. Um túnel faz a ligação entre os dois prédios e a exposição continua, no prédio $B$ com os módulos Jardim das Energias, Oícios da Mineração, Ofícios do Fogo, Ofícios da Madeira, Ofícios da Cerâmica, ofícios do Comércio, Ofícios da Lapidação e Ourivesaria, Ofícios do Couro, Ofícios da Terra, Ofícios da Conservação e Transformação dos Alimentos e Ofícios do Fio e do Tecido.

A coleção permitiu distintas abordagens narrativas, segundo Catel. Há conjuntos que possibilitam explorar determinadas profissões, determinadas técnicas, a origem geográfica comum ou contextos delimitados, assim como há objetos únicos, incorporados à coleção pela raridade. Para o museológo, as coleções "permitem fazer diferentes museus temáticos, permitem tomar uma posição essencialmente rural, local, essencialmente etnográfica”. (CATEL, 2005: 325).

Os objetos são introduzidos na exposição por meio de uma gramática expográfica que abrange dioramas, exibição de conjuntos tipológicos e destaque para alguns objetos únicos e/ou excepcionais. À exceção de alguns totens e legendas expandidas e dos dioramas que inserem o acervo em contextos do cotidiano do trabalho, prevalecem informações meramente técnicas referentes às características e fabricação dos objetos, insuficientes, portanto, ao propósito de dar a conhecer o universo material que cercava e cerca os ofícios pré-industriais. Em alguns módulos a profusão de objetos deixa em segundo plano ou mesmo oblitera a narrativa do ofício.

A configuração espacial da exposição, organizada em nichos temáticos, permite que o visitante, ao se deter em um módulo, não perca de vista o conjunto da exposição. Os espaços estão franqueados ao olhar, o que possibilita maior liberdade nas escolhas de percursos. Ainda que o formato da planta baixa de ambos os prédios ocupados pela exposição de longa duração seja retangular, o que poderia impor uma orientação de sentido linear, a narrativa não traduz uma ordem do tempo evolutivo. Não há, no percurso, um principio, meio e fim.

De fato, a proposta expositiva encerra uma linguagem atemporal. Não há tempo demarcado na exposição, embora se registre datas e períodos em etiquetas e legendas. Em termos de agenciamento do espaço, não existe uma ordem sequencial de módulos a ser seguida por um percurso fixo, assim como inexiste uma ordem temporal, que articule passado, presente e futuro, mas apenas a ideia de que o universo apresentado se situa no passado. Um passado atemporal, porque em constante presentificação, a alimentar a ilusão da intemporalidade, de que fala Crane (2006); ou seja, de que seria possível compartilhar o passado como se nunca tivesse passado.

A narrativa se constrói fazendo um apelo à memória afetiva da tradição; uma memória que ocorre fora do tempo, porque destituída da experiência e 
convertida em mito. Em alguns módulos, essa memória mítica é sublinhada por elementos caros à identidade regional, como no caso da cozinha mineira. O que se observa é que "não há tempo histórico, apenas a memória que se repõe numa ordem cíclica do tempo". (JULIÃO, 2015:I33).

Conclui-se, lembrando que nas cenografias dos dioramas é recorrente o uso de manequins que simulam o manuseio e funcionalidade de alguns dos objetos. Confeccionados em tecido neutro, sem feição ou qualquer detalhe de identificação social ou étnica, provavelmente foram concebidos apenas como suportes de cena, sem riscos de se criar imagens equivocadas dos trabalhadores dos ofícios, ou mesmo conduzir a identificações de determinados grupos sociais a ofícios específicos. Se por um lado esse é um argumento válido, por outro, os manequins tematizam, de alguma forma, a ausência do trabalhador na exposição. O museu trata do trabalho pré-industrial, mas o sujeito dessa experiência está invisibilizado. Não estaria o Museu reproduzindo o fetiche do mundo da produção, no qual as mercadorias - portanto, objetos - ganham protagonismo apagando o trabalho que foi empregado por sujeitos para produzi-los? Estaria aí a chave explicativa da atemporalidade da exposição, da narrativa subtraída de sua historicidade?

\section{Considerações Finais}

Os dois museus analisados - Museu Histórico Nacional (MHN), e o Museu de Artes e Ofícios (MAO) - com suas distintas narrativas e propostas expográficas, constituem experiências que ilustram diferentes temporalidades representadas em museus brasileiros. As análises de ambas as exposições evidenciam que a sociedade contemporânea alterna formas distintas de se relacionar com - passado. A representação do tempo numa perspectiva linear e cronológica, recorrentes em museus de história, como no caso do MHN, dificilmente poderá ensejar a construção de narrativas históricas concorrentes. $A$ linearidade predominante na exposição do MHN elege marcos temporais de uma história nacional, na qual não há lugar para aqueles que estão à margem, aqueles que habitam a periferia de narrativas históricas hegemônicas.

De outra parte, a experiência espaço-temporal da exposição do MAO renuncia à sua historicidade; não há ali conexões entre passado, presente e futuro e, por isso mesmo, a narrativa se projeta em um horizonte de suspensão temporal. Objetos referentes ao trabalho pré-industrial são apresentados, por conseguinte, sem evocar os sujeitos pertencentes ao contexto histórico em questão, subtraindo, dessa maneira, os conflitos e tensões que conferem sentido histórico à passagem do tempo, à experiência do passado.

Independentemente de suas distintas narrativas, ambas as exposições têm um ponto de convergência inegável: seja na representação do tempo linear e cronológico ou da atemporalidade mítica, dificilmente poderão contemplar uma Museologia e uma História descolonizada e descolonizadora. Porque em ambas as exposições não há lugar para que se "escove a história a contrapelo" de que fala Benjamin, de modo a romper e destronar o tempo contínuo, homogêneo e vazio da história. Talvez esse seja o maior desafio que se coloca para essas instituições: como dar lugar a histórias vencidas, de temporalidades fragmentárias, 
Tempo e Espaço como Experiência no Museu

nas quais escombros do passado visam o presente, não como rememoração ou reconstituição, mas como experiências do passado que são iluminadas por impasses e urgências do presente?

É a partir dessas inquietações que as análises das narrativas expositivas dos MHN e MAO inscrevem-se em uma tentativa de contribuir para o exercício de uma museologia crítica. Elegeu-se a articulação entre tempo e espaço como uma chave possível de interpretação de exposições, porque se compreende que são elementos que integram a cultura paradigmática de exibições. Em particular o ambiente expositivo é um ativador temporal. É por meio do processo de espacialização de acervos orientado pelo conceito curatorial, que as representações de tempo ganham materialidade como imagens e se oferecem à experiência sensível do público visitante. Nessa conjugação de elementos que fazem a exposição - curadoria, materialidade, imagens e experiência sensível - os museus podem ser compreendidos como produtos e também como produtores de espaço, na perspectiva assinalada por Milton Santos:

Espaço é algo dinâmico e unitário, onde se reúnem materialidade e ação humana. $\bigcirc$ espaço seria o conjunto indissociável de sistemas de objetos, naturais ou fabricados, e de sistemas de ações, deliberadas ou não. A cada época, novos objetos e novas ações vêm juntar-se às outras, modificando o todo, tanto formal quanto substancialmente. (SANTOS, 2008: 23)

Como incidências de ações humanas e objetos materiais, os museus e suas exposições se subordinam ao movimento do tempo, constituindo realidades históricas. É nessa condição que se pode desnaturalizar os elementos expográficos - disposição do acervo e sintaxe expositiva, vitrines, iluminação, etiquetagem, percursos - e compreendê-los como concorrentes na construção de narrativas museais. É nessa condição que museus e suas exposições poderão ser pensados como documentos das representações que a sociedade faz de si. Ou melhor, retornando mais uma vez a Benjamin, como documentos da cultura compreendidos na dimensão de documentos da barbárie.

\section{Referência Bibliográfica}

ABREU, R. (1996). A fabricação do imortal: memória, história e estratégia de consagração no Brasil. Rio de Janeiro: Rocco.

BAYER, Herbert. Fundamentals of exhibition design. Publicado na revista PM 6 (production manager) de dez/jan 1939/40, p. 17-25.

BENCHETRIT, S.F. \& Tostes, V. L. B. (Eds.), História representada: o dilema dos museus (pp.75-96). Rio de Janeiro: Museu Histórico Nacional.

BENNETT, Tony. Civic Seeing: Museums and the Organization of Vision. In: MACDONALD, Sharon (ed.). A Companion to Museum Studies. Oxford/UK, 2006, pp. 263-28I

BRUNO, M. C. O. (Coord.);ARAUJO, M. M.; COUTINHO, M. I. L. (Col.).A evidência dos contextos museológicos. In: . Waldisa Rússio Camargo Guarnieri: textos e contextos de uma trajetória profissional. São Paulo: Pinacoteca; ICOM, 20I0. v. I.

BRUNO, M. C. O. (Coord.); ARAUJO, M. M.; COUTINHO, M. I. L. (Col.).A permanência 
das ideias: a influência nos contextos museológicos. In: Guarnieri: textos e contextos de uma trajetória profissional. São Paulo: Pinacoteca; ICOM, 2010.v. 2.

CASTILLO, Sonia Salcedo del. Cenário da arquitetura da arte. São Paulo: Martins, 2008.

CATEL, P.: Belo Horizonte's Museum of Arts and Trades: after all, how are museums born? (Interview by Luciana Sepúlveda Köptcke). História, Ciências, Saúde - Manguinhos, v. 12 (supplement), p. 323-38, 2005.

CRANE, Susan A. The Conundrum of ephemerality: time, memory and museums. In: MACDONALD, Sharon (Ed.). A companion to museum studies. Malden, MA: Blackwell Pub., 2006. Pp. 98- 109

DESVALLÉES, André; MAIRESSE, François; eds. 2013. Conceitos-chave de Museologia.Tradução de Bruno Brulon Soares e Marilia Xavier Cury. ICOM.Armand Colin. ISBN: 97885-8256-025-9.

GIEBELHAUSEN, Michaela. The architecture is the museum. New Museum Theory and Practice:An Introduction. Blackwell Publishing: 2008.

GUIMARÃES, M. L. S. Memória, história e historiografia. In Bittencourt, J. N., 2003.

HARTOG, François. Regimes de Historicidade: presentismo e experiências do Tempo - I. Ed.; 2. Reimp. - Belo Horizonte:Autêntica Editora, 2015.

HILLIER, Bill;TZORTZI, Kali. Space Syntax:The Language of Museum Space. In: MACDONALD, Sharon, (ed.) A Companion to Museum Studies. (p. 282-30I). Blackwell Publishing Ltd: Oxford, UK. 2006

JULIÃO, Letícia. Museum and historicity:The representation of time in Brazilian museums. Icofom Study Series, v. 43a, p. II 9-129, 2015.

KNAUSS, Paulo. $O$ desafio de construir a História com imagens: arte e cultura visual. ArtCultura, Uberlândia, v. 8, n. 12, p. 97-I I5, jan.-jun. 2006

MAGALHÃES, A. M. (2003). Cultuando a saudade... Sobre antiquariado e escrita da história no MHNacional. In Bittencourt, J. N., Benchetrit, S.F. \& Tostes,V. L. B. (Eds.), História representada: o dilema dos museus (pp.97-I I 2). Rio de Janeiro: Museu Histórico Nacional.

MUSEU HISTÓRICO NACIONAL. A história da instituição. Disponível em: <https:// http://mhn.museus.gov.br/index.php/o-museu/> Acesso em: 20 de dezembro de 2017.

POMIAN, Krzyztof. Le musée face à I'histoire. In: L'Histoire au Musée. Actes du Colloque L'Histoire au Musée. Château de Versalles:ActesduSud, 2004.

PREZIOSI, Donald. Art History and Museology: Rendering the Visible Legible. In: MACDONALD, Sharon (ed.). A Companion to Museum Studies. (p. 50-63). Blackwell Publishing Ltd: Oxford, UK. 2006

ROUANET, Sérgio Paulo Rouanet (Tradução). In Walter Benjamin - Obras escolhidas. Vol. I. Magia e técnica, arte e política. Ensaios sobre literatura e história da cultura. Prefácio de Jeanne Marie Gagnebin. São Paulo: Brasiliense, 1987, p. 222-232.

SANTOS, MILTON. Técnica, espaço, tempo: Globalização e meio técnico-científico-informacional/Milton Santos. 5.Ed. São Paulo Editora da Universidade de São Paulo, 2008. 